\title{
KECERDASAN BUDAYA MAHASISWA CALON KONSELOR
}

\author{
Suciani Latif ${ }^{1}$
}

\begin{abstract}
The aim of this study is to produce a profile of cultural intelligence of student. Participants are students of Teacher Education Program-Counseling (PPG-BK) SM3T Makassar State University. Number of participants as many as 16 students consisting of 13 women and 3 men. The instrument used is the scale of cultural intelligence which is the result of adaptation and modification of Cultural Intelligence Scale developed by Early and Ang (2003). Data analysis used descriptive data analysis to describe the level of cultural intelligence of students. The results of this study indicate that students' cultural intelligence are mostly located in the high category. On average the results of each dimension is found that the dimensions of CI Metaconitive have the highest rates, followed by CI Motivation, and the lowest CI Cognitive Behavior. Discussion, limitations and recommendations discussed in the study.
\end{abstract}

Keywords: Counseling, Counselor, Cultural Intelligence, Cultural Competence.

JOMSIGN: Journal of Multicultural Studies in Guidance and Counseling

Website : http://ejournal.upi.edu/index.php/JOMSIGN

Permalink: http://ejournal.upi.edu/index.php/JOMSIGN/article/view/6314

How to cite (APA): Latif, S. (2017). Kecerdasan budaya mahasiswa calon konselor. JOMSIGN: Journal of Multicultural Studies in Guidance and Counseling, 1(2), 139-148.

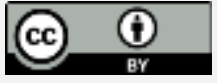

This is an open access article distributed under the terms of the Creative Commons Attribution 4.0 International License, which permits unrestricted use, distribution, and reproduction in any medium, provided the original work is properly cited.

\section{PENDAHULUAN}

Konsep tentang kecerdasan budaya pertama kali diperkenalkan oleh Early dan Soon Ang pada tahun 2003. Pada awalnya konsep tersebut muncul dan berkembang di kalangan bisnis global. Globalisasi yang terjadi telah meningkatkan interaksi antar budaya, sehingga meningkatkan kemungkinan terjadinya kesalahpahaman, ketegangan dan konflik budaya (Ang, Dyne, \& Tan, 2011). Kecerdasan Budaya mengacu pada kemampuan seseorang untuk berfungsi secara efektif dalam konteks budaya yang beragam (Ang dan Van Dyne 2008, Earley dan Ang 2003). Definisi ini sebagai suatu kemampuan menekankan potensi seseorang untuk menjadi efektif di berbagai konteks antar

${ }^{1}$ Universitas Negeri Makasar, Indonesia; suci.bkunm@gmail.com. 
budaya. Kecerdasan budaya berbeda dari kemampuan untuk berfungsi secara efektif dalam budaya tertentu. Sebaliknya, kecerdasan budaya mencerminkan seperangkat kemampuan umum yang memfasilitasi efektivitas seseorang di budaya yang berbeda dan dalam lingkungan multikultural (Ang, Soon, et al, 2015). Livermore (2011) mendefinisikan kecerdasan budaya sebagai kemampuan untuk berfungsi secara efektif dalam berbagai konteks budaya yang bervariasi.

Kecerdasan budaya serupa dengan kecerdasan yang berfokus pada domain konten tertentu, seperti kecerdasan sosial (Thorndike \& Stein, 1937), kecerdasan emosional (Mayer \& Salovey, 1993), dan kecerdasan praktis (Sternberg et al., 2000). Kecerdasan Budaya juga berfokus pada setting domain khusus, dan dimotivasi oleh realitas praktis globalisasi di tempat kerja (Earley \& Ang, 2003). Kecerdasan Budaya dikonseptualisasikan sebagai bentuk spesifik kecerdasan yang difokuskan pada kemampuan individu untuk memahami dan alasan yang benar dalam situasi yang ditandai dengan keragaman budaya. Sama seperti kecerdasan emosional (EQ) yang melengkapi kecerdasan kognitif (IQ), bahwa keduanya penting bagi seorang individu untuk menemukan keberhasilan di tempat kerja dan dalam hubungan pribadi di dunia yang semakin saling bergantung (Earley \& Gibson, 2002), Kecerdasan budaya merupakan bentuk lain yang melengkapi kecerdasan yang dapat menjelaskan variabilitas dalam menghadapi keragaman dan berfungsi dalam setting budaya baru. Karena norma-norma interaksi sosial bervariasi dari budaya ke budaya maka tidak mungkin kecerdasan kognitif, kecerdaan emosional, atau kecerdasan sosial akan diterjemahkan secara otomatis ke penyesuaian dan interaksi lintas budaya yang efektif (Ang et al, 2008).

Konseptualisasi kecerdasan budaya dibangun di atas wawasan dari kecerdasan Penelitian menunjukkan kecerdasan adalah multifaset. Mengintegrasikan berbagai pandangan tentang kecerdasan, Sternberg dan Detterman (1986) mengemukakan bahwa kecerdasan berada pada lokus indiferen dalam individu yakni biologi, kognisi (termasuk metakognisi), motivasi, dan perilaku.

Berdasarkan pandangan Sternberg \& Detterman inilah Earley dan Ang (2003) membangun model kecerdasan budaya yang terdiri dari empat dimensi: (1) kecerdasan budaya metakognitif, yang mencerminkan kemampuan mental individu untuk memperoleh dan memahami pengetahuan budaya; (2) kecerdasan budaya kognitif, yang mencerminkan pengetahuan individu tentang budaya dan perbedaan budaya; (3) kecerdasan budaya motivasi, yang 
mencerminkan kemampuan individu untuk mengarahkan dan mempertahankan usaha menuju berfungsi dalam situasi antarbudaya; dan (4) perilaku kecerdasan budaya, yang mencerminkan kemampuan individu untuk perilaku fleksibilitas dalam interaksi lintas budaya. Keempat dimensi ini dapat ditingkatkan melalui pelatihan, pengalaman, dan pendidikan. Oleh karena itu, kecerdasan budaya berkonsentrasi pada pengembangan kerangka teoritis global untuk mengidentifikasi dan memahami keterampilan, pengetahuan, dan perilaku budaya yang diperlukan untuk berfungsi secara efektif dalam masyarakat yang beragam budaya

Cultural Intelligance Scale (CQS) merupakan instrumen kecerdasan budaya berupa laporan diri (self-report) dan laporan observer (observer-report) (Ang et al, 2008). CQS ini mengukur 4 dimensi kecerdasan budaya yakni CI Metakognitif, CI Kognitif, CI Motivasi dan CI Perilaku. CQS telah diterima di seluruh dunia. Studi empiris tentang kecerdasan budaya telah dilakukan di Amerika Utara, Amerika Selatan, Eropa, Timur Tengah, Asia, Australia, dan Selandia Baru. Sampel termasuk ekspatriat, pebisnis internasional, buruh asing, domestik global, dan mahasiswa internasional. Secara keseluruhan, studi kecerdasan budaya memiliki sampel orang dari atau bekerja di setidaknya 40 negara yang berbeda. Di sampel ini, para sarjana telah mempelajari (1) anteseden dari kecerdasan budaya , (2) hasil kecerdasan budaya, (3) kecerdasan budaya sebagai mediator, (4) kecerdasan budaya sebagai moderator, dan (5) kondisi batas dari efek kecerdasan budaya. Beberapa penelitian secara teoritis dan empiris telah dilakukan terkait kecerdasan budaya untuk konstruk lain, seperti ciri-ciri kepribadian, kecerdasan emosional, kompetensi lintas budaya, penyesuaian lintas budaya, kepribadian multikultural, kompleksitas kognitif, dan kapital lintas budaya.

Konsep kecerdasan budaya pada dasarnya memiliki kemiripan dengan konsep kompetensi multibudaya dalam bidang bimbingan dan konseling. Istilah kompetensi multibudaya didefinisikan sebagai pengetahuan, kesadaran, dan keterampilan konselor yang digunakan dalam bekerja dengan beragam budaya konseli. Sebagai calon guru BK/konselor, mahasiswa jurusan Bimbingan dan Konseling perlu dibekali pengetahuan dan keterampilan multibudaya. Mengingat bahwa pada dasarnya semua proses konseling merupakan multibudaya, baik konselor maupun konseli membawa budayanya masingmasing ke dalam proses konseling. Dengan perspektif seperti ini, seorang calon 
guru $\mathrm{BK} /$ konselor perlu memiliki kompetensi multibudaya sebagai kompetensi dasar dalam proses konseling.

Pada tingkat Strata 1 (S1) Program Studi Bimbingan dan Konseling, wawasan tentang multibudaya tertuang dalam mata kuliah Bimbingan dan Konseling Multibudaya. Diharapkan melalui mata kuliah ini, kecerdasan budaya mahasiswa dapat dikembangkan agar mampu berinteraksi secara efektif dengan konseli yang berbeda latar belakang budaya. Namun kenyataannya, kajian multibudaya lebih banyak melalui kajian teori sementara praktik untuk memperkaya keterampilan multibudaya mahasiswa masih belum difokuskan. Selain itu, pada Program Pendidikan Guru Bimbingan dan Konseling/Konselor belum ada mata workshop secara khusus membangun kompetensi multibudaya konselor (Budiman, N, 2016). Oleh karena itu, pengembangan kecerdasan budaya pada calon guru BK/ konselor perlu dilaksanakan secara terencana. Sebagai langkah awal dalam mengembangkan kecerdasan budaya mahasiswa calon guru BK/konselor maka perlu studi awal tentang profil kecerdasan budaya mahasiswa. Berdasarkan hal tersebut di atas, dalam artikel ini akan disajikan tentang gambaran tingkat kecerdasan budaya mahasiswa berdasarkan 4 dimensi yakni CI Metacognitive, CI Cognitive, CI Motivation, dan CI Behavior . Melalui studi ini diharapkan akan menjadi rujukan dalam menyusun strategi pengembangan kecerdasan budaya mahasiswa calon guru BK/Konselor.

\section{METODE}

Studi ini menggunakan jenis penelitian survei analitik yakni survey cross sectional yaitu penelitian yang mempelajari dinamika kolerasi antara faktorfaktor sebab dengan akibat. Survey menggunakan instrumen Skala Kecerdasan Budaya yang telah diadaptasi dan dimodifikasi dari Cultural Intelligence Scale (CQS) (Early \& Ang, 2003).

Partisipan pada studi ini adalah 16 mahasiswa (13 perempuan dan 3 laki-laki). Partisipan merupakan mahasiswa Program Pendidikan Guru-Bimbingan dan Konseling (PPG-BK) SM3T Universitas Negeri Makassar. Mahasiswa yang menjadi partisipan adalah angkatan IV 2016. Pemilihan Mahasiswa PPG-BK SM3T sebagai partisipan dengan pertimbangan bahwa bahwa mereka adalah calon guru BK/konselor yang akan menyandang gelar Guru professional (Gr) dan telah memiliki pengalaman menjadi guru selama 1 tahun di daerah 3T. 
Instrumen yang digunakan dalam penelitian ini merupakan hasil adaptasi dan modifikasi dari instrumen yang dikembangkan oleh Early dan Ang (2003). Instrumen ini dikenal dengan Cultural Intelligence Scale (CQS). CQS memiliki 20 aitem dengan pilihan jawaban berada pada skala 1-7 ( 1 = strongly disagree; 7 = strongly agree $)$ dari 4 dimensi kecerdasan budaya. Dimensi tersebut adalah CI Metacognitive, CI Cognitive, CI Motivation, dan CI Behavior. Namun dalam studi ini 20 aitem tersebut dikembangkan menjadi 22 aitem dengan pilihan jawaban skala 1-7 (1= sangat tidak sesuai, 7=sangat sesuai). Masing-masing dimensi memiliki 5-6 aitem pernyataan. Instrumen disebarkan pada kelompok mahasiswa dan di uji validitas dan reliabilitas. Melalui uji statistik SPSS diperoleh hasil uji validitas berada pada taraf signifikansi $0.01(1 \%)$ dan reliabilitas sebesar 0,860 .

Partisipan adalah mahasiswa PPG-BK SM3T Universitas Negeri Makassar (UNM) Angkatan IV 2016. Instrumen diberikan di dalam kelas. Setiap pernyataan dibacakan dengan saksama sebelum partisipan memberikan jawaban. Partisipan diberi waktu selama 2 menit untuk menjawab setiap pernyataan. Hal ini dilakukan agar partisipan dapat memberikan pilihan jawabannya benar-benar sesuai dengan keadaan dirinya. Setelah dipastikan bahwa semua partisipan telah menuliskan jawabannya, instrumen dikumpulkan kembali dan peneliti meninggalkan ruangan kelas.

Data yang diperoleh dianalisis secara deskriptif. Kategori tingkat kecerdasan budaya secara umum dibagi menjadi tiga yakni rendah, sedang dan tinggi. Kategori Rendah $=22-66$, Sedang $=67-111$ dan Tinggi $=112-156$. Sementara untuk menilai hasil dari setiap dimensi dari kecerdasan budaya maka dilakukan perhitungan rerata (mean). Berdasarkan kategori ini akan terlihat tingkat kecerdasan budaya mahasiswa secara umum serta kecerdasan budaya pada setiap dimensinya.

\section{HASIL DAN PEMBAHASAN}

Hasil analisis data disajikan dalam dua bagian. Bagian pertama gambaran kecerdasan budaya mahasiswa secara umum dan bagian kedua gambaran kecerdasan budaya pada 4 dimensi yaitu CI Metacognitive, CI Cognitive, CI Motivation, dan CI Behavior. 


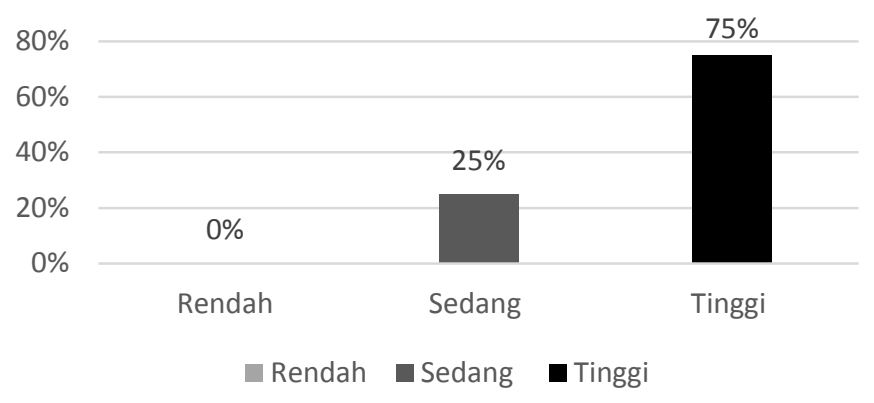

Gambar 1. Grafik Presentase Kecerdasan Budaya Mahasiswa

Pada Gambar 1 diketahui bahwa kecerdasan budaya mahasiswa PPG-BK SM3T UNM Angkatan IV 2016 berada pada kategori Tinggi sebanyak 12 Orang (75\%) dan Sedang sebanyak 4 Orang (25\%).

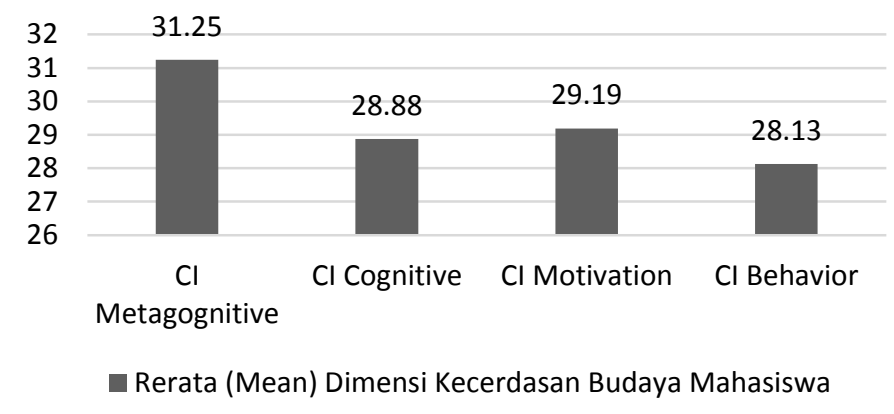

Gambar 2. Grafik Rerata Dimensi Kecerdasan Budaya

Pada Gambar 2 dapat diketahui bahwa dimensi CI Metaconitive memiliki rerata tertinggi yakni 31,25 disusul oleh CI Motivation 29,19, CI Cognitive yakni 28,88 dan terendah CI Behavior yakni 28,13.

Studi ini bertujuan untuk menghasilkan profil tentang kecerdasan budaya mahasiswa secara umum dan pada setiap dimensinya. Pada hasil analisis diketahui bahwa kecerdasan umum mahasiswa sebagian besar berada pada kategori tinggi. Hal ini berarti mahasiswa PPG-BK SM3T UNM memiliki kecerdasan budaya yang tinggi dimana mencerminkan bahwa mahasiswa telah memiliki kemampuan untuk memahami, berpikir dan berperilaku secara efektif dalam situasi multibudaya. Tingginya kecerdasan budaya mahasiswa ini dipengaruhi oleh pengalaman mereka bertemu dengan orang-orang yang berbeda budaya dengan dirinya saat mengemban tugas selama 1 tahun di daerah 3T (Terdepan, Terluar dan Tertinggal) seperti di daerah Aceh, Papua, NTT, Natuna dan daerah 3T lainnya. Selama bertugas mereka dituntut untuk beradaptasi dengan kondisi lingkungan, sosial, hukum, adat dan kebiasaan yang 
ada dalam masyarakat setempat. Menurut Livermore (2011), berinteraksi dengan berbagai budaya dapat meningkatkan kecerdasan budaya seseorang.

Dimensi CI Metacognitive memiliki skor rerata tertinggi yang artinya mahasiswa memiliki kesadaran dan kemampuan dalam menetapkan strategi yang dapat membuatnya efektif dalam interaksi multibudaya. Dengan kata lain, sebagai calon konselor mereka mampu menyusun strategi budaya selama interaksi konseling multibudaya. Konselor yang memiliki rencana metakognitif tinggi, tercermin dalam setiap interaksi konseling. Mereka mampu mengubah pemahaman dan perilaku dalam interaksi lintas budaya sebagai panggilan berdasarkan pergeseran informasi dan lingkungan. Sebagai suatu trait, metakognitif memiliki karakteristik serupa dengan konseptualisasi kesadaran multikultural dari Sue dan Torino (2005).

Dalam profesi konseling, kesadaran akan bias budaya sendiri sangat penting dalam menerangkan pemicu dan konsekuensi dari dinamika interaksi seseorang dengan individu yang beragam budaya. Hal ini merupakan kombinasi dari refleksi secara terus-menerus pada kesadaran, bersama dengan kemampuan dan kemauan untuk mengubah perilaku yang diperlukan agar sesuai dengan tuntutan interaksi lintas budaya, yang memungkinkan untuk latihan kompeten secara budaya. Dalam dua studi kompetensi budaya (Goh \& Yang, 2007; Goh, Starkey, Skovholt \& Jennings, 2007), praktisi yang kompeten secara budaya secara konsisten menunjukkan keluwesan secara kognitif dan mudah beradaptasi dan terus-menerus menyusun strategi dengan cara yang lebih baik untuk berkomunikasi dan berhubungan antar budaya.

Dimensi CI Motivation menempati posisi kedua rerata tertinggi. Hal ini berarti bahwa mahasiswa memiliki motivasi yang cukup dalam berinteraksi dalam situasi multibudaya. Dengan kata lain, mahasiswa memiliki drive intrinsik untuk belajar, memahami, dan beradaptasi dengan budaya yang beragam dan keadaan konseli yang kompleks budaya. Dimensi motivasi mencerminkan kemampuan intrinsik individu untuk mencari dan menikmati interaksi dengan orang beragam budaya secara konsisten. Melibatkan motivasi dalam konseling multibudaya tidak secara eksplisit ditangani oleh model kompetensi konseling multikultural dari Sue et al (1982). Dengan kata lain, model kompetensi oleh Sue tidak menterjemahkan secara langsung peningkatan motivasi konselor dalam bekerja dengan konseli. Akibatnya konselor terpaksa bekerja dengan beragam konseli tanpa mengungkapkan bagaimana gambaran motivasi mereka dalam berinteraksi dengan konseli yang beragam. Perbedaan sikap antara konselor mengenai pentingnya bekerja dengan individu yang beragam, serta 
variasi dalam kepercayaan diri mereka tentang kemampuan untuk secara efektif memperlakukan konseli dari budaya yang berbeda akan sangat mempengaruhi kinerja konselor dalam bekerja dengan konselinya.

Dimensi CI Cognitive memiliki rerata tertinggi ketiga dalam studi ini. Dimensi kognitif didefinisikan sebagai pengetahuan tentang aspek budaya lingkungan dan tempat seseorang di dalamnya, dan secara luas meliputi budaya universal dan perbedaan budaya (Ang et al., 2007). Dengan kata lain, mahasiswa cukup memiliki pengetahuan tentang budaya konseli, termasuk nilai-nilai, normanorma, dan lingkungan. Dimensi kognitif ini memiliki kemiripan dengan komponen pengetahuan dalam Model tripartit kompetensi budaya dari Sue \& Sue (2003). Aspek kognitif ini penting dalam memahami dinamika interaksi sosial dengan individu dari budaya tertentu. Hal ini dioperasionalkan sebagai pengetahuan termasuk ekonomi, pernikahan, dan sistem hukum, serta keyakinan agama secara umum, aturan bahasa, seni dan kerajinan, nilai-nilai budaya, dan pola perilaku nonverbal dari budaya lain. Faktor ini menggabungkan kedua pengertian etik (yang universal budaya) dan emic perspektif (budaya tertentu) dalam konseling (Sue \& Sue, 2003). Sue \& Sue menegaskan bahwa sangat penting konselor akrab dengan latar belakang budaya konseli mereka. Selain itu, konselor perlu membentuk rasa empati kognitif dengan konseli agar dapat melihat dan menerima pandangan dunia lain dengan cara yang tidak menghakimi (Sue \& Sue, 2003).

Nilai rerata terendah dari 4 dimensi ini adalah CI Behavior. Meskipun memiliki metakonitif yang tinggi, mahasiswa kurang terampil dalam berperilaku saat dalam situasi multibudaya secara tepat. Dalam arti konseptual yang luas, dimensi perilaku mencerminkan komponen keterampilan dari kompetensi multikultural. Sue \& Sue (2003) menggambarkan keterampilan konseling multikultural penting karena menggabungkan respon verbal dan nonverbal yang sesuai dengan budaya, mendukung perubahan kelembagaan yang mewakili konseli dan beradaptasi dengan ekspektasi peran konseli. Dalam hal ini, konselor menerapkan faktor-faktor lain dari kecerdasan budaya dalam mode yang dapat diamati dan diukur. Konseling pada dasarnya didasarkan pada pertukaran verbal; tanpa penggunaan kata-kata yang tepat, serta keheningan (silence), konselor tidak akan mungkin dapat menjangkau konseli. Mengingat bahwa gaya komunikasi cenderung bervariasi dalam multibudaya, penting bagi konselor untuk mengadopsi gaya fleksibel sehubungan dengan berkomunikasi dengan orang lain dalam situasi yang multibudaya (Goh et al., 2008). 


\section{SIMPULAN}

Hasil studi ini menunjukkan bahwa kecerdasan budaya mahasiswa sebagian besar berada pada kategori tinggi. Hal ini berarti mahasiswa telah memiliki kemampuan yang tinggi untuk memahami, berpikir dan berperilaku secara efektif dalam situasi multibudaya. Pada hasil rerata setiap dimensinya ditemukan bahwa dimensi CI Metaconitive memiliki rerata tertinggi disusul oleh CI Motivation, CI Cognitive dan terendah CI Behavior. Hal ini berarti bahwa CI Behavior mengalami perkembangan yang sedikit dibanding dengan ketiga dimensi lainnya.

Studi ini memiliki keterbatasan. Pertama, penggunaan metode laporan diri untuk survei CQS. Meski telah divalidasi, metode laporan diri memiliki objektivitas yang kurang. Selain itu, penelitian terakhir telah menunjukkan bahwa mengukur CI Cognitive melalui laporan diri tidak reliabel (Imai dan Gelfand, 2010). Oleh karena itu, penelitian selajutnya harus mencakup langkahlangkah lebih objektif untuk melaporkan kecerdasan budaya, seperti penilaian sejawat dan observasi. Kedua, fakta bahwa survei hanya pada mahasiswa PPGBK SM3T UNM sehingga membatasi generalisasi hasil. Penelitian lebih lanjut perlu menilai kecerdasan budaya pada sampel yang lebih luas dari PPG-BK yang tersebar di beberapa wilayah di Indonesia. Akhirnya, penelitian ini hanya berfungsi sebagai potret dari tingkat kecerdasan budaya mahasiswa PPG-BK SM3T sehingga diharapkan studi ini memberikan kontribusi dalam penyusunan kurikulum Bimbingan dan Konseling berbasis multibudaya.

\section{REFERENSI}

Ang, S., Van Dyne, L., Koh, C., Ng, K. Y., Templer, K. J., Tay, C., \& Chandrasekar, N. A. (2007). Cultural intelligence: Its measurement and effects on cultural judgment and decision making, cultural adaptation and task performance. Management and organization review, 3(3), 335-371.

Ang, S., Dyne, L. V., \& Rockstuhl, T. (2015). Cultural intelligence: Origins, conceptualization, evolution, and methodological diversity. In M. J. Gelfand, Chi-Yue Chiu, \& Ying-Yi Hong (Eds.). Handbook of Advances in Culture and Psychology Volume 5. New York: Oxford University Press. pp. 273-324.

Ang, S., \& Dyne, L. V. (2008). Handbook of cultural intelligence: Theory, measurement, and applications. New York: ME Sharpe.

Ang, S., Dyne, L. V., \& Tan, M. L. (2011). Cultural intelligence. In Robert J. Sternberg \& Scott Barry Kaufman, (Eds.). The Cambridge Handbook of Intelligence. Cambridge University Press, pp. 582-602. 
Ang, S., Rockstuhl, T., \& Tan, M. L. (2015). Cultural intelligence and competencies. International encyclopedia of social and behavioral sciences, 2, 433-439.

Budiman, N. (2016). Pendidikan Profesional Konselor Multibudaya (Studi Pengembangan Pendidikan Profesional Konselor Berbasis Kompetensi Multibudaya. Sekolah Pascasarjana Universitas Pendidikan Indonesia. Bandung.

Earley, P.C., \& Ang, S. (2003). Cultural intelligence: Individual interactions across cultures. Palo Alto, CA: Stanford University Press.

Earley, P.C., \& Gibson, C.B. (2002). Multinational work teams: A new perspective. Hillsdale, NJ: Lawrence erlbaum.

Goh, M., Koch, J., \& Sanger, S. (2008). Cultural intelligence in counseling psychology: Applications for multicultural counseling competence. In S. Ang \& L. Van Dyne (Eds.), Handbook of cultural intelligence (pp. 257270). Armonk, NY: M.E. Sharpe.

Goh, M., Starkey, M., Skovholt, T.M., \& Jennings, L. (2007). In search of cultural competence in mental health practice: a study of expert multicultural counseling therapists. Paper presented at the $115^{\text {th }}$ annual convention of the american psychological association, San Francisco, CA.

Goh, M., \& Yang, A. (2007). The developmental model of intercultural sensitivity: A study of culturally competent exemplars. Paper presented at the 115th annual convention of the American Psychological Association, San Francisco, CA.

Imai, L., \& Gelfand, M. J. (2010). The culturally intelligent negotiator: The impact of cultural intelligence (CQ) on negotiation sequences and outcomes. Organizational Behavior and Human Decision Processes, 112(2), 83-98.

Livermore, D. (2011). The cultural intelligence difference: Master the one skill you can't do without in today's global economy. AMACOM Div American Management Association.

Sternberg, R. J., \& Detterman, D. K. (1986). What is intelligence? Contemporary viewpoint on its nature and definition. Norwood, NJ: Ablex.

Sternberg, R. J., Forsythe, G. B., Hedlund, J., Horvath, J. A., Wagner, R. K., Williams, W. M., Snook, S., \& Grigorenko, E. L. (2000). Practical intelligence in everyday life. New York: Cambridge University Press.

Sue, D. W., \& Sue, D. (2003). Counseling the culturally diverse: Theory and practice $\left(4^{\text {th }}\right.$ ed.). New York: John Wiley \& Sons.

Thorndike, R. L., \& Stein, S. (1937). An evaluation of the attempts to measure social intelligence. Psychological Bulletin, 34(5), 275-285. 